\title{
BẢO TỒN DÂY CHẰNG TỐI ĐA TRONG PHẪU THUẠT THAY VAN HAI LÁ HẬU THẤP TẠI BỆNH VIỆN ĐÀ NÃNG
}

Nguyễn Minh Hải*

\section{TÓM TẮT}

Mục tiêu nghiên cứu này nhằm đánh giá hiệu quả của kỹ thuật bảo tồn dây chằng tối đa trong phẫu thuật thay van hai lá hậu thấp. Từ $1 / 2015$ đến 12/2015, tại bệnh viện Đà Nẵng, 36 trường hợp bệnh van hai lá hậu thấp được thay van nhân tạo, sử dụng kỹ thuật bảo tồn dây chằng cả lá trước và sau.Kích thước thất trái đo trên siêu âm tim lúc ra viện giảm có ý nghĩa thống kê $(\mathrm{P}<0,01)$, nhưngkhông có sự khác biệt về phân xuất tống máu (EF) so với trước mổ.Không có biến chứng hẹp đường ra thất trái, vỡ thất trái, kẹt van nhân tạo, hoặc tử vong.Kỹ thuật này có thể thực hiện cho bệnh van hai lá hậu thấp và cho thấy sự cải thiện tốt chức năng thất trái trong ngắn hạn.

\section{SUMMARY:}

Mitral valve replacement with maximum chordal preservation in a rheumatic population at Da Nang hospital.The aim of this study is to investigate theeffect of chordal-sparing mitral valve replacement proceduresin a rheumatic population.Between January and December 2015, 36 patients underwent mitral valve replacement for rheumatic heart disease at Da Nang hospital.Reduction of left ventricular end-systolic and end-diastolic diameteris significant postoperative as compared to preoperative ( $\mathrm{p}<0,01$ ), but ejection fraction do not change statistically.There is no death ormyocardial rupture.Echocardiographic follow-up is complete and there has been no evidence of left ventricular outflow tract obstruction or interference with prosthetic valve function by the retained subvalvular structures.We conclude that maximum chordal preservation is possible in the large majority of rheumatic patients with acceptable operativemortality and satisfactory short-term results.

\section{I. ĐẠTT VẤN ĐỀ}

Bệnh van hai lá hậu thấp cho đến nay vẫn khá phổ biến tại Việt Nam. Với các tổn thương van quá nặng không còn phù hợp cho sửa van thì chỉ định thay vantimnhân tạo là cần thiết. Đã có nhiều báo cáo chứng minh việc đảm bảo tính liên tục giữa vòng van hai lá và cơ nhú giúp cải thiện chức năng thất trái sau mổ tốt hơn hẳn so với việc cắt bỏ toàn bộ dây chằng trong phẫu thuật thay van hai lá. Đồng thời việc bảo tồn toàn bộ dây chằng cũng tốt hơn là chỉ bảo tồn dây chằng lá sau [4],[5]. Nghiên cứu này nhằm đánh giá hiệu quả của kỹ thuật bảo tồn dây chằng tối đa trong phẫu thuật thay van hai láhậu thấp tại bệnh viện Đà Nẵng*

\section{II. ĐỐI TƯợNG VÀ PHƯớg PHÁP NGHIÊN CỨU}

Nghiên cứu mô tả tiến cứu từ $1 / 2015$ đến 12/2015, tại bệnh viện Đà Nẵng có 36 trường hợp bệnh van hai láhậu thấp được phẫu thuật thay van nhân tạo cơ học. Loại khỏi nghiên cứu các trường hợp thay van hai lá không do thấphoặc kèm theo bắc cầu động mạch vành.Các trường hợp có chỉ định sửa van hai lá cũng loại khỏi nghiên cứu này.

Tất cả bệnh nhân đều được chuẩn bị trước mổ, kỹ thuật thực hiện, chăm sóc hậu phẫu và theo dõi sau mổ theo một chương trình soạn sã̃n.Số liệu được phân tích và xử lý bằng phần mềm SPSS.

Kỹ thuật mổ: qua đường mở dọc giữa xương ức, máy tim phổi nhân tạo được thiết lập, bảo vệ cơ tim bằng dung dịch liệt tim máu lạnh $4^{\circ} \mathrm{C}-8^{\circ} \mathrm{C}$, không hạ thân nhiệt. Tiếp cận van hai lá qua đường mở nhĩ trái hoặc vách liên nhĩ.Cắt rời lá trước ra

\footnotetext{
Bệnh viện Đà Nã̃ng
}

Người chịu trách nhiệm khoa hoc: Nguyên Minh Hải

Ngày nhận bài: 05/04/2016 - Ngày Cho Phép Đăng: 05/05/2016

Phản Biện Khoa học: PGS.TS. Đặng Ngoc Hùng GS.TS. Lê Ngọc Thành 
khỏi vòng van cũng như lá sau tại hai mép van.Tiếp tục xẻ đôi lá trước ở vị trí 12 giờ để chia thành hai nhóm dây chằng tương ứng với hai cơ nhú.Loại bỏ các mô lá van vàdây chằng lá trước đã dầy dính, co rút, vôi hoá nặng.Các dây chằng còn tốt của cột cơ trước bên và sau giữa được bảo tồn cùng với dải mô lá van rộng từ 5 đến $10 \mathrm{~mm}$ và lần lượt đượckhâu lại vào vòng van tại vị trí 9 giờ và 3 giờ tương ứng. Sử dụng chính các mũi chỉ chữ ' $U$ ' khâu van tim nhân tạo để gắn các dây chằng lá trước vào vòng van. Nếu dải mô lá van gắn với dây chằng thừa nhiều mà không thể cắt nhỏ hơn, cần chú ý dùng móc (hook) kéo về phía nhĩ của vòng van khi buộc chỉ khâu van để tránh mô thừa gây hẹp đường ra thất trái hoặc ảnh hưởng đến hoạt động của van nhân tạo. Lá sau van hai lá được xẻ từ bờ tự do cho đến sát vòng van ở vị trí 6 giờ, có thể xẻ thêm 2-3 đường tương tự để chia lá sau làm nhiều đoạn nhằm làm tăng thêm diện tích lỗ van và đặt được van nhân tạo lớn hơn.Loại bỏ các mô van vôi hoá cũng như các dây chằng bị dầy dính, co rút quá nặng trên lá sau.Mô thừa lá van được khâu gấp cuộn vào vòng van bằngchính các mũi rời chữ ' $U$ ' dùng khâu van nhân tạo.Sau khi đã buộc chỉ khâu van, cần kiểm tra và cắt gọt bớt các mô thừa và dây chằng nếu còn gây ảnh hưởng đến hoạt động của van nhân tạo.Khi tổn thương van hai lá quá nặng buộc phải cắt bỏ toàn bộ dây chằng, chỉ Gore-Tex 4/0 được sử dụng để làm dây chằng nhân tạo.Dùng mũi chữ ' $\mathrm{X}$ ' khâu qua phần đỉnh xơ của cơ nhú trước bên và sau giữa, sau đấy lần lượt khâu xuyên qua vòng van ở vị trí 9 giờ và 3 giờ tương ứng. Các mũi chỉ này tiếp tục được khâu qua van hai lá nhân tạo, và từng sợi được buộc lại sau khi đã đặt van nhân tạo vào đúng vị trí cũng như đã buộc xong các mũi chỉ khâu van. Cần chú ý độ dài của chỉ Gore-Tex sao cho vừa phải để cơ nhú cũng như dây chằng nhân tạo không quá căng hay quá lỏng.

\section{KẾT QUẢ NGHIÊN CÚU}

Từ tháng 1/2015 đến 12/2015 đã có 36 trường hợp tổn thương van hai lá do thấp được chỉ định phẫu thuật thay van hai lá nhân tạo cơ học và bảo tồn dây chằng tối đa. Các phẫu thuật phối hợp đồng thời bao gồm: thay van động mạch chủ $(22,2 \%)$; sửa van ba lá (58,3\%); lấy huyết khối và khâu tiểu nhĩ trái $(13,9 \%)$. Các dây chằng van hai lá còn tốt đều được giữ lại, chỉ có 3 trường hợp toàn bộ dây chằng của một cơ nhú bị tổn thương nặng phải cắt bỏ nên được thay thế bằng chỉ Goretex (bảng 1).

\section{Bảng 3.1: Dây chằng đự̣c bảo tồn}

\begin{tabular}{|l|l|l|}
\hline \multicolumn{2}{|l|}{ Dây chằng được bảo tồn } & Thông số \\
\hline \multirow{3}{*}{ Lá trước } & Hai nhóm dây chằng & $22(61,1 \%)$ \\
\cline { 2 - 3 } & Một nhóm dây chằng & $12(33,3 \%)$ \\
\cline { 2 - 3 } & Không bảo tồn được & $2(5,6 \%)$ \\
\hline \multirow{3}{*}{ Lá sau } & Toàn bộ dây chằng & $14(38,9 \%)$ \\
\cline { 2 - 3 } & $2 / 3$ dây chằng & $13(36,1 \%)$ \\
\cline { 2 - 3 } & $1 / 2$ dây chằng & $9(25 \%)$ \\
\hline
\end{tabular}

Thời gian thở máy trung bình sau mổ là 20,2 $\pm 23,4$ giờ. Có 15 trường hợp sử dụng kết hợp dobutamine và adrenaline sau mổ, số còn lại chỉ dùng một loại thuốc vận mạch với thời gian trung bình là 2,7 2 2,1 ngày. Kích thước thất trái đo trên siêu âm tim sau mổ giảm có ý nghĩa thống kê so với trước mổ $(\mathrm{P}<0,01)$, nhưng không có sự khác biệt về phân xuất tống máu (EF) (bảng 2). 


\section{Bảng 3.2: Thay đổi trên siêu âm tim}

\begin{tabular}{|l|l|l|l|}
\hline & Trước mổ & Sau mổ & P \\
\hline LVIDd(mm) & $48,08 \pm 8,89$ & $44,94 \pm 6,84$ & 0,004 \\
\hline LVIDs(mm) & $32,64 \pm 7,91$ & $30,22 \pm 6,33$ & 0,007 \\
\hline EF(\%) & $60,44 \pm 7,93$ & $60,64 \pm 7,18$ & 0,893 \\
\hline
\end{tabular}

Ba loại van hai lá nhân tạo được sử dụng: 7 ca dùng số $25 ; 27$ ca dùng số 27 và chỉ có 2 ca dùng số 29. Chênh áp tối đa qua van nhân tạo là $9,2 \pm 2,8$ mmHg và không có có sự khác biệt có ý nghĩa thống kê giữa các cỡ van khác nhau. Theo dõi cho đến nay, không có trường hợp nào bị hẹp đường ra thất trái, vỡ thất trái, kẹt van hai lá nhân tạo, hoặc tử vong.

\section{BÀN LUẬN}

Các tổn thương van hai lá đặc biệt là do hậu thấp không phải lúc nào cũng có thể sửa chữa thành công. Khi đó, thay van tim nhân tạo là giải pháp duy nhất để điều trị cho người bệnh. Đã có nhiều tác giả nêu lên tầm quan trọng của việc bảo tồn dây chằng trong phẫu thuật thay van hai lá.Nó không chỉ giúp cải thiện chức năng thất trái ngắn hạn cũng như lâu dài tốt hơn so với phẫu thuật thay van hai lá kinh điển với dây chằng bị cắt bỏ, mà còn ngăn ngừa biến chứng rất nặng sau mổ là nguy cơ vỡ thất trái nhờ vẫn đảm bảo tính liên tục của thất trái và vòng van hai lá [1],[2],[4]. Việc bảo tồn dây chằng cần đảm bảo ba nguyên tắc cơ bản: không gây hẹp đường ra thất trái; mô van giữ lại không ảnh hưởng đến hoạt động của van nhân tạo;và phải đặt được cỡ van phù hợp với người bệnh [1],[2].

Cả 36 trường hợp thay van hai lá trong nghiên cứu này đều do tổn thương thấp, vì vậy toàn bộ hệ thống dây chằng và mô lá van đều bị dầy dính, co rút và vôi hoá ở các mức độ khác nhau tuỳ từng bệnh nhân. Về lâu dài sau mổ các cấu trúc van hai lá được bảo tồn có nguy cơ tiếp tục tiến triển tổn thương thấp gây ảnh hưởng đến hoạt động của van tim nhân tạo. Do vậy, chúng tôichỉchọn lọc giữ lại những mô lá van chưa bị vôi hoá, nhữngdây chằng còn tương đối mềm mại và không bịdầy dính, co ngắn nhiều.Đối với các dây chằng lá trước giữ lại được chia làm hai nhóm gắn với dải mô lá van: nhóm tương ứng với cột cơ nhú trước bên sẽ khâu lại vào vòng van hai lá ở vị trí 9 giờ; nhóm còn lại tương ứng với cơ nhú sau giữa sẽ khâu vào vị trí 3 giờ.Kỹ thuậtgiữ toàn bộ dây chằng lá trước và gắn lại vào vòng van tương ứng với vị trí giải phẫu[1],[3] thường không phù hợp cho các tổn thương do thấp vì nhiều khả năng làm hạn chếhoạt động của van nhân tạo. Ngay cả với lá van sau, nhiều tác giả chỉ sẻ lá van thành hai hoặc nhiều đoạn và giữ toàn bộ dây chằng [1],[2],[4] nhưng chúng tôi chủ động loại bỏ tất cả tổn thương vôi hoá cũng như những dây chằng đã dầy dính và co rút nặng. Nhờ vậy, theo dõi cho đến nay chưa ghi nhận trường hợp nào bị hẹp đường ra thất trái hoặc kẹt van tim nhân tạo cơ học do cấu trúc được bảo tồn gây ra.

Trong bệnh van tim hậu thấp, việc giữ được tất cả dây chằng van hai lá thường rất khó khăn. Chúng tôi cố gắng đảm bảo sao cho mỗi cơ nhú đều có dây chằng được bảo tồn. Tuy vậy, trong nghiên cứu nàycó 3 trường hợp cả dây chằng lá trước và lá sau của cùng một cơ nhú bịtổn thương nặng phải loại bỏ nên chúng tôi đã sử dụng chỉ Goretex $4 / 0$ để làm dây chằng nhân tạo thay thế. Mỗi cơ nhú chỉ cần làm một dây chằng và chiều dài của nó được đo tương đương với dây chằng giữ lại của người bệnh. Cách đo độ dài như vậy sẽ tránh việc dây chằng nhân tạo quá ngắn gây nguy cơ đứt cơ nhú về sau, 
hoặc quá dài sẽ không còn tác dụng cải thiện chức năng thất trái.

Khi bảo tồn dây chằng tối đa, thường sẽ phải đặt cỡ van hai lá nhân tạo nhỏ hơn. Khoảng hơn $80 \%$ trường hợp trong nghiên cứu này được sử dụng van số 27 và 29 , gần $20 \%$ còn lại dùng van số 25. Tuy nhiên chúng tôi không nhận thấy sự khác biệt có ý nghĩa thống kê về chênh áp tối đa qua van hai lá nhân tạo đo trên siêu âm tim sau mổ ở các loại cỡ van khác nhau.

Trong nghiên cứu này, không ghi nhận trường hợp nào bị vỡ thất trái hoặc tử vong trong và sau mổ. Đặc biệt chức năng thất trái được cải thiện sớm ngay sau mổ với thời gian thở máy trung bình sau mổ là 20,2 $\pm 23,4$ giờ. Có 41,7\% trường hợp sử dụng kết hợp dobutamine và adrenaline sau mổ, số còn lại chỉ dùng một loại thuốc với thời gian dùng thuốc vận mạch trung bình là $2,7 \pm 2,1$ ngày và liều thuốc từtrung bình đến thấp. Ngay khi xuất viện, kích thước thất trái đo trên siêu âm tim sau mổ giảm có ý nghĩa thống kê $(\mathrm{P}<0,01)$,đồng thời không có sự suy giảmvề phân suất tống máu thất trái so với trước mổ.

\section{KẾT LUẬN}

Việc bảo tồn dây chằng tối đa trong phẫu thuật thay van hai lá hậu thấp khôngquá phức tạp về kỹ thuật.Trong ngắn hạn, cho thấy sự cải thiện tốt chức năng thất trái.Tuy nhiên về lâu dài, cần tiếp tục nghiên cứu,đánh giá các nguy cơ do tổn thương thấp tác động đến van nhân tạo trên một cỡ mẫu đủ lớn.

\section{TÀI LIỆU THAM KHẢO}

1. Colleen F. Sintek, MD, Thomas A. Pfeffer, MD, Gary S. Kochamba, MD, and Siavosh Khonsari, MD.Mitral Valve Replacement: Technique to Preserve the Subvalvular Apparatus. Ann Thorac Surg 1995;59:1027-9.

2. Faruk Cingo“ z, M.D., Celalettin Gu“ nay, M.D., Erkan Kuralay, M.D., et al.Both Leaflet Preservation During Mitral Valve Replacement: Modified Anterior Leaflet Preservation Technique. J Card Surg 2004;19:528-534.

3. Hideki Sasaki, Kenji Ihashi. Chordal-sparing mitral valve replacement: pitfalls and techniques to prevent complications. European Journal of Cardio-thoracic Surgery 24 (2003) 650-652.

4. Kwok L. Yun, MD; Colleen F. Sintek, MD; D. Craig Miller, MD; et al. Randomized Trial of Partial Versus Complete Chordal Preservation Methods of Mitral Valve Replacement. Circulation. 1999;100[suppl II]:II-90 -II-94.

5. Ujjwal K. Chowdhury, MCh, A. Sampath Kumar, MCh, Balram Airan, MCh, et al. Mitral Valve Replacement With and Without Chordal Preservation in a Rheumatic Population: Serial Echocardiographic Assessment of Left Ventricular Size and Function. Ann Thorac Surg 2005;79:1926-33. 